\title{
THE CHARACTERISTICS AND OUTCOMES OF TOXIN-INDUCED MASSIVE RHABDOMYOLYSIS
}

\author{
WOJCIECH WALDMAN ${ }^{1,2}$, JACEK SEIN ANAND ${ }^{1,2}$, and PIOTR KABATA ${ }^{2}$ \\ ${ }^{1}$ Medical University of Gdańsk, Gdańsk, Poland \\ Faculty of Health Division, Department of Clinical Toxicology \\ ${ }^{2}$ Pomeranian Center of Toxicology, Gdańsk, Poland
}

\begin{abstract}
Objectives: This study investigates common patterns in patients with exceptionally high creatine kinase (CK) levels to identify factors that could have contributed to the development of severe rhabdomyolysis in the studied cohort. Material and Methods: The authors present a retrospective analysis of patients with massive rhabdomyolysis (measured CK activity $>50000 \mathrm{U} / \mathrm{l}$ ) caused by xenobiotics. The patients were selected from a group of 7708 patients treated at the Regional Toxicological Center. Results: The most frequent causative agents were recreational drugs, sedatives and anti-epileptics. Six patients developed multi-organ failure, including 1 who died. Substance abuse disorder was diagnosed in $90 \%$ of the patients. Each patient had at least 1 contributory factor present (hypothermia, hyperthermia, injury, an episode of agitation, seizures, prolonged immobilization), and the median was 3 factors. Acute kidney injury was observed in $90 \%$ of the patients, and $70 \%$ needed renal replacement therapy due to acute renal failure, which meant a longer hospital stay. Creatinine concentration differences between days 2 and 1 of the presentation $\left(\mathrm{C}_{\text {diff }}\right)$ correlated with the length of hospital stay $(r=0.73, p=0.02)$. All patients with negative $\mathrm{C}_{\text {diff }}$ values did not need dialysis. No patients experienced liver failure. Conclusions: Massive rhabdomyolysis seems to be the effect of coincidence of several factors rather than the myotoxic effect alone. A creatinine concentration difference between days 2 and 1 of hospitalization was a good prognostic factor for the need for further dialysis. Int J Occup Med Environ Health. 2020;33(5):661-73
\end{abstract}

Key words:

drugs, acute kidney injury, rhabdomyolysis, acute poisoning, musculoskeletal injury, novel psychoactive substance

\section{INTRODUCTION}

Polypharmacy and an ongoing rise in the popularity of novel psychoactive substance (NPS) use brings a plethora of new toxins that can induce rhabdomyolysis, sometimes very severe, in patients. An adequate and quick treatment of this condition causes quick reversal of organ injuries leading to a shorter hospital stay and reduced healthcare costs.

Rhabdomyolysis is a syndrome caused by myocyte damage. It consists of clinical and biochemical features that are the result of the release of muscle cell contents. Some of those substances are available on most laboratories' standard test panels, i.e., myoglobin concentration, creatine kinase (CK) activity, and the levels of electrolytes, lactate dehydrogenase (LDH), alanine aminotransferase (ALT), and aspartate aminotransferase (AST). Other compounds (phospholipase A, $\mathrm{Ca}^{2+}$-dependent phosphorylases, nucleases, proteases, and free radicals) may require advanced analytical methods while not adding any substantial clinical value. Importantly, these substances are relevant in the development of complications of rhabdomyolysis. Muscle cells are affected either by direct cell membrane

Received: August 26, 2019. Accepted: May 22, 2020.

Corresponding author: Wojciech Waldman, Medical University of Gdańsk, Faculty of Health Division, Department of Clinical Toxicology, Kartuska 4/6, 80-104 Gdańsk, Poland (e-mail: waldman.wojciech@gmail.com). 
destruction or by energy depletion. Free ionized calcium enters the intracellular space and activates proteases and apoptosis pathways. The genesis and pathophysiology of rhabdomyolysis has been well studied [1-3].

Unfortunately, there is no published work on the mechanisms by which toxic substances trigger the process described above.

Rhabdomyolysis was first observed by Bywaters and Beal [4] in 1941, during their study of crush syndrome in victims saved from ruins after London bombings. This work led to the identification of the role played by myoglobin in the development of rhabdomyolysis. In addition to traumatic causes, $>150$ medications and toxins have been associated with myotoxic properties that lead to the development of rhabdomyolysis. The most prevalent causes of myocyte damage are recreational drugs and ethanol [5].

Non-traumatic rhabdomyolysis, which appears to be at least 5 times more common than traumatic rhabdomyolysis, may be a consequence of toxic injury caused by:

- medications,

- illicit drugs,

- plant toxins,

- animal poisons,

- electrolyte and metabolic disorders,

- infections,

- neuroleptic malignant syndrome (NMS),

- serotonin syndrome (SS),

- dermatomyositis and polymyositis.

Most authors emphasize the influence of toxic factors on the muscles. However, in this study, massive rhabdomyolysis was observed relatively rarely despite the fact that $43.2 \%$ of the intoxicated patients seen at the center had abnormal CK activity. The authors aimed to determine the cause of the relatively small proportion of patients who developed massive rhabdomyolysis. They formulated the following question: is the toxic effect of xenobiotics overestimated as a causative agent of muscle damage?

\section{MATERIAL AND METHODS}

\section{Study design and inclusion criteria}

This work presents 10 patients with massive rhabdomyolysis caused by toxic factors. Their CK activity levels ranged 1017.45-8609.30 ukat/l (61 035-516455 U/l). Data were gathered by retrospective analyses of the medical records of 7708 individuals treated at the Regional Toxicological Center in a large academic city in northern Poland, in 2009-2014. In total, 2397 patients had both their CK activity levels and creatinine concentrations measured. Of this group, 1036 (43.22\%) patients had elevated CK activity levels. Severe elevation, defined as CK activity > 833.5 ukat/l (50 $000 \mathrm{U} / \mathrm{l})$, was present in 10 patients, who were then enrolled in the analysis. According to observations made by the authors, just above this $\mathrm{CK}$ value, the risk of acute kidney damage and subsequent multi-organ failure (MOF) increased significantly.

Data regarding the agents causing rhabdomyolysis were obtained from anamnesis, qualitative testing using immunoassays and, where applicable, quantitative analysis.

An experienced team of specialists ruled out other conditions that can produce similar symptoms, such as NMS, SS, anti-cholinergic toxicity, heat stroke, and meningitis. None of the patients in the assessed group met the criteria for SS, malignant hyperthermia or meningitis. The results of routine laboratory tests were analyzed for both similarities and differences.

A specific ethical approval was not required for this observational study due to the nature of the study design.

\section{Study aim}

During the analysis, the authors tried to find common patterns in patients who developed severe rhabdomyolysis, and to identify factors that could have contributed to its development in the studied cohort.

\section{RESULTS}

In the analyzed period, 10 patients were identified who met the inclusion criteria. The group consisted of 1 woman 
and 9 men. The youngest individual was 20 years old, and the oldest 49 years old (mean 32, median 31, interquartile range [IQR] 27-36.75 years).

\section{Causative agents}

The authors analyzed the medical records looking for information regarding the substances that were involved in causing the condition of these patients. Table 1 presents a summary of the agents involved and shows the groups to which the substance belonged (grouping was performed according to the International Classification of Diseases, 10th revision, ICD 10) [6]. The most prevalent groups of substances involved in massive rhabdomyolysis were narcotics and psychodysleptics (7 patients); anti-epileptic, sedative-hypnotic and anti-parkinsonian drugs (6 patients); and psychotropic drugs, not elsewhere classified (3 patients). No individual substance was identified as having an outstanding prevalence. The authors were able to measure the concentration of only 5 out of the 22 substances involved. For the patient with 6 reported substances, they were able to perform a qualitative analysis. For the remaining patients, data regarding the substance used came either from the patient or from his/her family.

\section{Comorbidities}

Each patient in the study was evaluated by either a consultant psychiatrist or a specialist in substance dependence therapy, or by both. The diagnoses for each patient are presented in Table 2. The most prevalent finding was the harmful use of stimulants other than cocaine $(\mathrm{N}=4)$. Most of the studied patients $(\mathrm{N}=9)$ presented with some substance use disorder (ICD code group F10-F19). Of this group, 2 patients were treated due to NMS after the introduction of additional medication to the therapy.

The authors also analyzed comorbidities, both preexisting and complications of rhabdomyolysis. Kidney injury was excluded because it was analyzed separately. The most common maladies accompanying rhabdomyolysis were pneumonia $(\mathrm{N}=3)$ and various injuries $(\mathrm{N}=3)$. Only 1 patient died; however, that patient's death was a result of septic complications, not rhabdomyolysis. Most of the patients $(\mathrm{N}=7)$ had used psychoactive substances:

- NPSs $(\mathrm{N}=2)$,

- amphetamine $(\mathrm{N}=2)$,

- ethanol $(\mathrm{N}=2)$,

- opioids $(\mathrm{N}=1)$,

- lysergic acid diethylamide (LSD) $(\mathrm{N}=1)$,

- tetrahydrocannabinol (THC) $(\mathrm{N}=1)$.

Values do not add up to 7 due to multi-substance use by 1 patient. In 4 patients, pharmaceuticals were involved (all involved the ingestion of multiple drugs), and $1 \mathrm{pa}-$ tient was treated due to a severe acute withdrawal state with delirium. Most patients ( $\mathrm{N}=9$, all males) were diagnosed with substance abuse disorder, and 2 (1 male, 1 female) were diagnosed with NMS.

\section{Contributing factors}

Table 3 shows the presence of factors that might have potentially influenced the development of rhabdomyolysis. In 8 patients, agitation or aggression was present. Most patients $(60 \%, \mathrm{~N}=6)$ had body temperature disturbances; 4 had hyperthermia $\left(\geq 38^{\circ} \mathrm{C}\left[100.4^{\circ} \mathrm{F}\right]\right)$, and 2 had hypothermia $\left(\leq 35.0^{\circ} \mathrm{C}\left[95.0^{\circ} \mathrm{F}\right]\right)$. Five patients had seizures; injuries were present in 3 cases; and 3 patients had sustained prolonged immobilization. Each patient had at least 1 contributing factor, and the median was 3 factors. The authors could not exclude the possibility of a patient having had $\geq 1$ of the factors present prior to hospitalization, which were not noted in the medical history (especially in the cases of patients found unconscious with no prior information on the course of exposure).

\section{Laboratory deviations \\ Impact on kidney function}

Creatinine concentrations were analyzed on the day of admission (C1) and on the second day of hospitalization (C2). 
Table 1. Toxic agent confirmation in a retrospective analysis of patients with massive rhabdomyolysis (measured CK activity $>50000 \mathrm{U} / \mathrm{l}$ ) caused by xenobiotics, selected from a group of 7708 patients treated at the Regional Toxicological Center in northern Poland, in 2009-2014

\begin{tabular}{|c|c|c|c|c|c|c|}
\hline \multirow{3}{*}{ Participant } & \multirow{3}{*}{$\begin{array}{c}\text { Age } \\
\text { [years] }\end{array}$} & \multirow{3}{*}{ Sex } & \multirow{3}{*}{ Primary diagnosis (ICD-10) } & \multicolumn{3}{|c|}{ Confirmation } \\
\hline & & & & \multicolumn{2}{|c|}{ laboratory } & \multirow{2}{*}{ anamnesis } \\
\hline & & & & qualitative & quantitative & \\
\hline 1 & 31 & $\mathrm{M}$ & $\begin{array}{l}\text { NPS poisoning: 2-CB, MXE and drug } \\
\text { poisoning: THC, amphetamine } \\
\text { (T40.6, T40.7, T40.4) }\end{array}$ & yes - partial & no & no \\
\hline 2 & 20 & M & NPS poisoning: 25I-NBOMe (T40.6) & no & yes & no \\
\hline 3 & 20 & M & $\begin{array}{l}\text { CDI: } 400 \text { mg tamoxifen, } 2000 \mathrm{mg} \text { ibuprofen, } \\
2500 \mathrm{mg} \text { melperone, } \\
225 \mathrm{mg} \text { zopiclone, } 1500 \mathrm{mg} \text { pregabalin } \\
\text { (T38.6, T39.3, T43.4, T42.6, T42.5) }\end{array}$ & no & no & yes \\
\hline 4 & 37 & M & $\begin{array}{l}\text { amphetamine intoxication - 2-day binge } \\
\text { (T40.4) }\end{array}$ & yes & no & no \\
\hline 5 & 36 & M & $\begin{array}{l}\text { CDI: }>400 \mathrm{mg} \text { baclofen, } 1500 \mathrm{mg} \text { diclofenac, } \\
\text { ethanol (T42.8, T39.3, T51.0) }\end{array}$ & no & yes - partial & yes \\
\hline 6 & 40 & M & acute suicidal opioid intoxication (T40.1) & yes & no & no \\
\hline 7 & 30 & M & lysergide (LSD) intoxication (T40.8) & yes & no & no \\
\hline 8 & 31 & M & $\begin{array}{l}\text { CDI: } 3200 \mathrm{mg} \text { carbamazepine, } 400 \mathrm{mg} \\
\text { zolpidem, } 600 \mathrm{mg} \text { chlorprothixene (T42.1, } \\
\text { T42.6, T43.4) }\end{array}$ & yes & yes - partial & no \\
\hline 9 & 26 & $\mathrm{~F}$ & $\begin{array}{l}\text { CDI: clozapine, valproic acid intoxication } \\
(\mathrm{T} 43.5, \mathrm{~T} 42.6)\end{array}$ & no & yes - partial & yes \\
\hline 10 & 49 & M & acute alcohol poisoning (T51.0) & no & yes & no \\
\hline
\end{tabular}

ICD-10 - International Classification of Diseases, 10th Revision.

2-CB - 2,5-dimethoxy-4-bromophenethylamine: a psychedelic drug of the 2C family; 25I-NBOMe - a synthetic hallucinogen; CDI - combined drug intoxication; LSD - lysergic acid diethylamide: a hallucinogenic drug; MXE - methoxetamine: a dissociative hallucinogen; NPS - novel psychoactive substance; THC - tetrahydrocannabinol: one of cannabinoids identified in cannabis.

Additionally, the difference between those 2 values $\left(\mathrm{C}_{\text {diff }}\right)$ was calculated. The mean change in creatinine concentration was $48.63 \mathrm{umol} / \mathrm{l}(0.55 \mathrm{mg} / \mathrm{dl})(\mathrm{min} .91 .07 \mathrm{umol} / \mathrm{l}$ [1.03 mg/dl], max $150.31 \mathrm{umol} / 1$ [1.70 mg/dl]). All patients in whom the creatinine level decreased over the first day of hospitalization $(\mathrm{N}=3)$ had a $\mathrm{CK}$ activity level of $\leq 1648.38 \mathrm{ukat} / \mathrm{l}(98883 \mathrm{U} / \mathrm{l})$. None of those patients needed renal replacement therapy (RRT).

The need for RRT associated with a more severe and complicated course of poisoning had a significant impact on the length of hospital stay. The mean hospital stay was
4.33 days (min. 4, max 5, IQR 4-4.5, $\mathrm{N}=3$ ) in the no RRT group vs. 28.86 days (min. 20, max 36, IQR 25.50-32.50, $\mathrm{N}=7$ ) in the RRT group. The Welch 2-sample t-test showed statistical significance in the difference in means $(p<0.001)$. There was a significant correlation between $\mathrm{C}_{\text {diff }}$ and the length of hospital stay (Pearson's $r .=0.73, p=0.02$ ). The correlation between the length of hospital stay and the total duration of RRT was not statistically significant (Pearson's r. $=0.61, \mathrm{p}=0.15$ ).

The data regarding the renal parameters in the studied group are shown in Table 4. 
Table 2. Comorbidities in a retrospective analysis of patients with massive rhabdomyolysis (measured CK activity $>50000 \mathrm{U} /$ ) caused by xenobiotics, selected from a group of 7708 patients treated at the Regional Toxicological Center in northern Poland, in 2009-2014

\begin{tabular}{lll}
\hline Participant & \multicolumn{1}{c}{ Psychiatric diagnosis (ICD-10) } & \multicolumn{1}{c}{ Comorbidity (ICD-10) } \\
\hline 1 & harmful use of stimulants other than cocaine (F15.1) & $\begin{array}{l}\text { pneumonia (J15), bradycardia (R00.1), asystole (I46.9), } \\
\text { decubitus of groin region }\end{array}$ \\
& harmful use of stimulants other than cocaine (F15.1) & $\begin{array}{l}\text { compartment syndrome (T79.6), atrial fibrillation (I48), } \\
\text { supraventricular tachycardia (I47.1), sinus bradycardia } \\
\text { (R00.1) }\end{array}$ \\
3 & $\begin{array}{l}\text { NMS (G21.0) } \\
\text { harmful use of alcohol (F10.1) } \\
\text { mental and behavioral disorders due to use of other }\end{array}$ & superficial head injury (S00.80) \\
stimulants (F15.2), harmful use of stimulants other \\
than cocaine (F10.1) \\
alcohol dependence syndrome (F10.2) \\
dependence syndrome due to the use of multiple drugs \\
$\begin{array}{l}\text { and alcohol (F19.2), unspecified mood [affective] } \\
\text { disorder (F29) }\end{array}$
\end{tabular}

ICD-10 - International Classification of Diseases, 10th Revision.

DIC - disseminated intravascular coagulation; HCV - hepatitis C virus infection; NMS - neuroleptic malignant syndrome.

\section{Impact on liver function}

Table 5 presents the measured hepatic parameters (AST, ALT, international normalized ratio [INR]) and CK activity. Both aminotransferase activity levels were high (mean AST 2310 U/1, mean ALT 910.5 U/1). There were strong statistically significant correlations between their activity levels and $\max C K(r=0.91 ; r=0.97$, respectively). There was no correlation between the measured CK activity and INR.

\section{Electrolyte disturbances}

Table 6 presents the electrolyte concentrations observed at the time of hospital admission.
The most common observation was decreased ionized calcium concentration $\left(\mathrm{N}=9\right.$, mean $\mathrm{Ca}^{2+}$ concentration $=$ $1.06 \mathrm{mmol} / \mathrm{l})$. The only patient with a normal $\mathrm{Ca}^{2+}$ concentration had hypercalcemia. The second prevalent finding was hyperkalemia $(\mathrm{N}=8$, mean $\mathrm{K}$ concentration $=5.6 \mathrm{mmol} / \mathrm{l})$.

\section{Acid-base disturbances}

Every patient admitted to hospital had arterial blood drawn for the arterial blood gas (ABG) analysis. The results of those tests are shown in Table 7.

In the studied group, 5 patients were acidotic, 4 had normal $\mathrm{pH}$, and 1 had alkalosis. The mean $\mathrm{pH}$ was 7.31, 
Table 3. Factors contributing to rhabdomyolysis in a retrospective analysis of patients with massive rhabdomyolysis (measured CK activity $>50000 \mathrm{U} / 1$ ) caused by xenobiotics, selected from a group of 7708 patients treated at the Regional Toxicological Center in northern Poland, in 2009-2014

\begin{tabular}{|c|c|c|c|c|c|c|}
\hline Participant & $\begin{array}{l}\text { Temperature } \\
\text { disturbances }\end{array}$ & Injury & $\begin{array}{c}\text { Prolonged } \\
\text { immobilization }\end{array}$ & $\begin{array}{l}\text { Agitation/ } \\
\text { aggression }\end{array}$ & Seizures & Other contributory factors \\
\hline 1 & hyperthermia & no & no & yes & yes & none \\
\hline 2 & hyperthermia & no & no & yes & yes & none \\
\hline 3 & hyperthermia & no & yes & yes & no & $\begin{array}{l}\text { in the last few months } \\
\text { intensively trained in the gym } \\
\text { and used supplements for body } \\
\text { builders (creatine) }\end{array}$ \\
\hline 4 & none & yes & no & yes & yes & none \\
\hline 5 & hypothermia & no & yes & no & no & none \\
\hline 6 & hypothermia & no & yes & yes & no & $\begin{array}{l}\text { weekly binge drinking, } \\
\text { alcohol withdrawal syndrome, } \\
\text { hypotension, emaciation }\end{array}$ \\
\hline 7 & none & yes & no & yes & no & none \\
\hline 8 & none & yes & no & yes & yes & polydrug use \\
\hline 9 & hyperthermia & no & no & no & no & none \\
\hline 10 & none & no & no & yes & yes & alcohol withdrawal syndrome \\
\hline
\end{tabular}

Hyperthermia $\geq 38^{\circ} \mathrm{C}\left(100.4^{\circ} \mathrm{F}\right)$; hypothermia $\leq 35.0^{\circ} \mathrm{C}\left(95.0^{\circ} \mathrm{F}\right)$.

Table 4. Renal parameters in severe rhabdomyolysis in a retrospective analysis of patients with massive rhabdomyolysis (measured CK activity $>50000 \mathrm{U} / \mathrm{l}$ ) caused by xenobiotics, selected from a group of 7708 patients treated at the Regional Toxicological Center in northern Poland, in 2009-2014

\begin{tabular}{lccccccccc}
\hline Participant & AKI & $\begin{array}{c}\mathrm{C} 1 \\
{[\mathrm{mg} / \mathrm{dl}]}\end{array}$ & $\begin{array}{c}\mathrm{C} 2 \\
{[\mathrm{mg} / \mathrm{dl}]}\end{array}$ & $\begin{array}{c}\mathrm{C}_{\text {diff }} \\
{[\mathrm{mg} / \mathrm{dl}]}\end{array}$ & RRT & $\begin{array}{c}\text { CRRT } \\
{[\mathrm{h}]}\end{array}$ & IHD & Max CK & $\begin{array}{c}\mathrm{T}_{\text {hosp }} \\
{[\mathrm{n}]}\end{array}$ \\
\hline 1 & yes & 3.56 & 3.83 & 0.27 & yes & 288 & $3 \times 5 \mathrm{~h}(15 \mathrm{~h})$ & 220531 & 31 \\
2 & yes & 2.19 & 2.91 & 0.72 & yes & 696 & $4 \times 4 \mathrm{~h}(16 \mathrm{~h})$ & 516455 & 34 \\
3 & yes & 2.85 & 4.55 & 1.7 & yes & 96 & $4 \times 4 \mathrm{~h}(16 \mathrm{~h})$ & 131950 & 20 \\
4 & no & 0.7 & 0.50 & -0.2 & no & 0 & 0 & 61035 & 4 \\
5 & yes & 3.2 & 4.83 & 1.63 & yes & 216 & $1 \times 6 \mathrm{~h}(6 \mathrm{~h})$ & 97476 & 36 \\
6 & yes & 3.19 & 3.68 & 0.49 & yes & 360 & $2 \times 6 \mathrm{~h}(12 \mathrm{~h})$ & 169700 & 30 \\
7 & no & 2.66 & 1.63 & -1.03 & no & 0 & 0 & 93883 & 5 \\
8 & no & 2.26 & 1.27 & -0.99 & no & 0 & 0 & 85983 & 4 \\
9 & yes & 2.32 & 3.84 & 1.52 & yes & 0 & $4 \times 6 \mathrm{~h}(24 \mathrm{~h})$ & 225785 & 26 \\
10 & yes & 5.02 & 6.42 & 1.4 & yes & 144 & $6 \times 6 \mathrm{~h}(36 \mathrm{~h})$ & 270000 & 25 \\
\hline
\end{tabular}

AKI - acute kidney injury; $\mathrm{C} 1$ - creatinine on admission day; $\mathrm{C} 2$ - creatinine on the second day of hospitalization; $\mathrm{C}_{\text {diff }}$ - difference between $\mathrm{C} 1$ and $\mathrm{C} 2$ values; CRRT - continuous renal replacement therapy; IHD - intermittent haemodialysis; max CK - peak creatine kinase activity; RRT - renal replacement therapy; $\mathrm{T}_{\text {hosp }}$ - number of days of hospital stay. 
Table 5. Clinical hepatic injury markers in a retrospective analysis of patients with massive rhabdomyolysis (measured CK activity $>50000 \mathrm{U} / \mathrm{l}$ ) caused by xenobiotics, selected from a group of 7708 patients treated at the Regional Toxicological Center in northern Poland, in 2009-2014

\begin{tabular}{|c|c|c|c|c|}
\hline Participant & $\begin{array}{c}\text { INR }^{\mathrm{a}} \\
\text { (ref. 0.8-1.2) }\end{array}$ & $\begin{array}{c}\mathrm{AST}^{\mathrm{b}} \\
{[\mathrm{U} / \mathrm{l}]} \\
\text { (ref. 5-37) }\end{array}$ & $\begin{array}{c}\text { ALT }^{\mathrm{c}} \\
{[\mathrm{U} / \mathrm{l}]} \\
\text { (ref. 5-37) }\end{array}$ & $\begin{array}{c}\operatorname{Max} \mathrm{CK}^{\mathrm{d}} \\
{[\mathrm{U} / \mathrm{l}]} \\
(\text { ref. }<200)\end{array}$ \\
\hline 1 & 1.9 & 4140 & 1097 & 220531 \\
\hline 2 & 1.28 & 5327 & 3077 & 516455 \\
\hline 3 & 1.2 & 2131 & 477 & 131950 \\
\hline 4 & 1.28 & 823 & 298 & 61035 \\
\hline 5 & 1.25 & 1621 & 639 & 97476 \\
\hline 6 & 0.92 & 1298 & 638 & 169700 \\
\hline 7 & 1.04 & 1132 & 238 & 93883 \\
\hline 8 & 0.98 & 642 & 223 & 85983 \\
\hline 9 & 1.21 & 2742 & 764 & 225785 \\
\hline 10 & 1.28 & 3242 & 1654 & 270000 \\
\hline
\end{tabular}

ref. - reference value.

ALT - alanine aminotransferase; AST - alanine aminotransferase; INR - international normalized ratio, max CK - maximal creatine kinase activity.

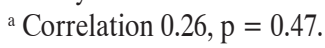

${ }^{\mathrm{b}}$ Correlation 0.91, $\mathrm{p}<0.0001$.

${ }^{\mathrm{c}}$ Correlation $0.97, \mathrm{p}<0.0001$.

${ }^{\mathrm{d}}$ Correlation 1, $\mathrm{p}<0.0001$.

(min. 7.15, max 7.47, IQR 7.242-7.383). All patients had components of metabolic acidosis in their ABG analysis; in 3 patients, it was primary metabolic acidosis; in 4 patients, it was acute, uncompensated respiratory acidosis; and in 4 patients, mixed respiratory alkalosis was observed together with metabolic acidosis.

In the analyzed group, 7 patients had increased anion gaps (mean $10.63 \mathrm{mmol} / \mathrm{l}$, min. 4.04, max $16.00 \mathrm{mmol} / \mathrm{l}$, IQR $10.32-11.07 \mathrm{mmol} / \mathrm{l})$.

\section{Complete blood count alterations}

All patients had leucocytosis with a shift towards younger cells in an automatic blood smear. Most patients had a predominance of neutrocytes, and $80 \%$ of patients were anemic and presented with thrombocytopenia.

\section{Complications of rhabdomyolysis}

In the studied group, 6 patients developed MOF. Among those individuals, 1 death was observed. Due to acute renal failure, 7 patients needed RRT. Additionally, 7 patients developed respiratory failure that required mechanical ventilation. The most prevalent complication was pneumonia, which was present in 4 patients. Severe hypotension, disseminated intravascular coagulation, and compartment syndrome were also observed, each of which was present in 2 patients. A summary of the observed complications is presented in Table 8.

\section{DISCUSSION}

Rhabdomyolysis is a process of muscular tissue damage that results in the release of cell contents into 
Table 6. Electrolyte disturbances in patients with massive rhabdomyolysis in a retrospective analysis of patients with massive rhabdomyolysis (measured CK activity $>50000 \mathrm{U} / \mathrm{l}$ ) caused by xenobiotics, selected from a group of 7708 patients treated at the Regional Toxicological Center in northern Poland, in 2009-2014

\begin{tabular}{|c|c|c|c|c|c|c|}
\hline Participant & $\begin{array}{c}\mathrm{K} \\
{[\mathrm{mmol} / \mathrm{l}]} \\
(\mathrm{N} 3.5-5.1)\end{array}$ & $\begin{array}{c}\mathrm{Na} \\
{[\mathrm{mmol} / \mathrm{l}]} \\
(\mathrm{N} 136-145)\end{array}$ & $\begin{array}{c}\mathrm{Ca} \\
{[\mathrm{mmol} / \mathrm{l}]} \\
(\mathrm{N} 8.8-10.2)\end{array}$ & $\begin{array}{c}\mathrm{Ca}^{2+} \\
{[\mathrm{mmol} / \mathrm{l}]} \\
(\mathrm{N} 1.12-1.32)\end{array}$ & $\begin{array}{c}\mathrm{P} \\
{[\mathrm{mmol} / \mathrm{l}]} \\
(\mathrm{N} 2.5-4.5)\end{array}$ & $\begin{array}{c}\mathrm{Cl} \\
{[\mathrm{mmol} / \mathrm{l}]} \\
(\mathrm{N} 98-107)\end{array}$ \\
\hline 1 & 7.1 & 139 & 7.63 & 0.99 & 5.03 & 116 \\
\hline 2 & 5.3 & 140 & 7.72 & 1.05 & 6.02 & 112 \\
\hline 3 & 7.1 & 136 & 11.23 & 1.16 & 3.01 & 107 \\
\hline 4 & 3.5 & 117 & 8.8 & 1.06 & 2.08 & 84 \\
\hline 5 & 6.3 & 136 & 6.7 & 1.09 & 10.01 & 111 \\
\hline 6 & 9.5 & 135 & 7.92 & 1.01 & 2.03 & 97 \\
\hline 7 & 5.5 & 143 & 9.2 & 1.04 & 3.03 & 103 \\
\hline 8 & 4.9 & 130 & 8.9 & 1.10 & 2.06 & 103 \\
\hline 9 & 5.2 & 156 & 9.2 & 1.06 & 4.03 & 121 \\
\hline 10 & 5.8 & 125 & 9.13 & 1.01 & 5.08 & 96 \\
\hline
\end{tabular}

$\mathrm{N}-$ norm.

$\mathrm{Ca}$ - total calcium; $\mathrm{Ca}^{2+}$ - ionized calcium; $\mathrm{Cl}$ - chloride; $\mathrm{K}$ - potassium; $\mathrm{Na}$ - sodium; $\mathrm{P}$ - inorganic phosphorus.

the bloodstream. The released substances include electrolytes, myoglobin, and enzymes (CK, LDH, ALT, AST). Muscle damage may be a result of many factors, including crushing, burning, vasoconstriction or vasal obstruction leading to tissue hypoxia, excessive physical activity, prolonged seizures or immobilization. The effects of medications, recreational drugs, plant toxins, animal venoms, electrolyte or metabolic disturbances, infections, SS and NMS are other factors leading to rhabdomyolysis [7].

In clinical practice, the extent of muscular damage is monitored by $\mathrm{CK}$ activity and myoglobin concentration. There is no established cut-off value for diagnosing muscular pathology; however, it has been frequently assumed that the threshold for rhabdomyolysis diagnosis is a CK activity level higher than $5 \times$ the normal value (approx. 16.67 ukat/l [1000 U/l]) [8]. The increase in CK activity is usually visible $4-6 \mathrm{~h}$ after the stress, and it can be observed for 24-48 h. In the case of massive rhabdomyolysis, the normalization of CK activity can start several days after the stress [9]. According to Childs [10], CK activity in patients with massive rhabdomyolysis is usually between 166.7 and >1667 ukat/l (10 000 and >100 $000 \mathrm{U} / \mathrm{l})$.

Myoglobin is the second parameter that can be measured in the cases of suspected muscular damage. Its use is limited by its half-life of 2-3 h [11], and the lack of a strong correlation between its blood and/or urine concentrations and the severity of rhabdomyolysis [12].

The incidence of rhabdomyolysis is controversial, and there are many discrepancies in the literature. In the USA, approximately 26000 cases of rhabdomyolysis are diagnosed every year [13]. According to Veenstra et al. [14], over the observation period of 7 years, in a study performed in a large university hospital, only $0.074 \%$ of patients had CK activity levels >83.35 ukat/l (5000 U/l). Janković et al. [15] analyzed 656 patients hospitalized over 1 year due to intoxication with various substances; CK >4.17 ukat/l ( $250 \mathrm{U} / 1$ ) was present in $19 \%$ of these patients. In the group of analyzed cases with abnormal CK values, patients with CK ranging 25.01-166.7 ukat/l (1500-10 000 U/l) was pres- 


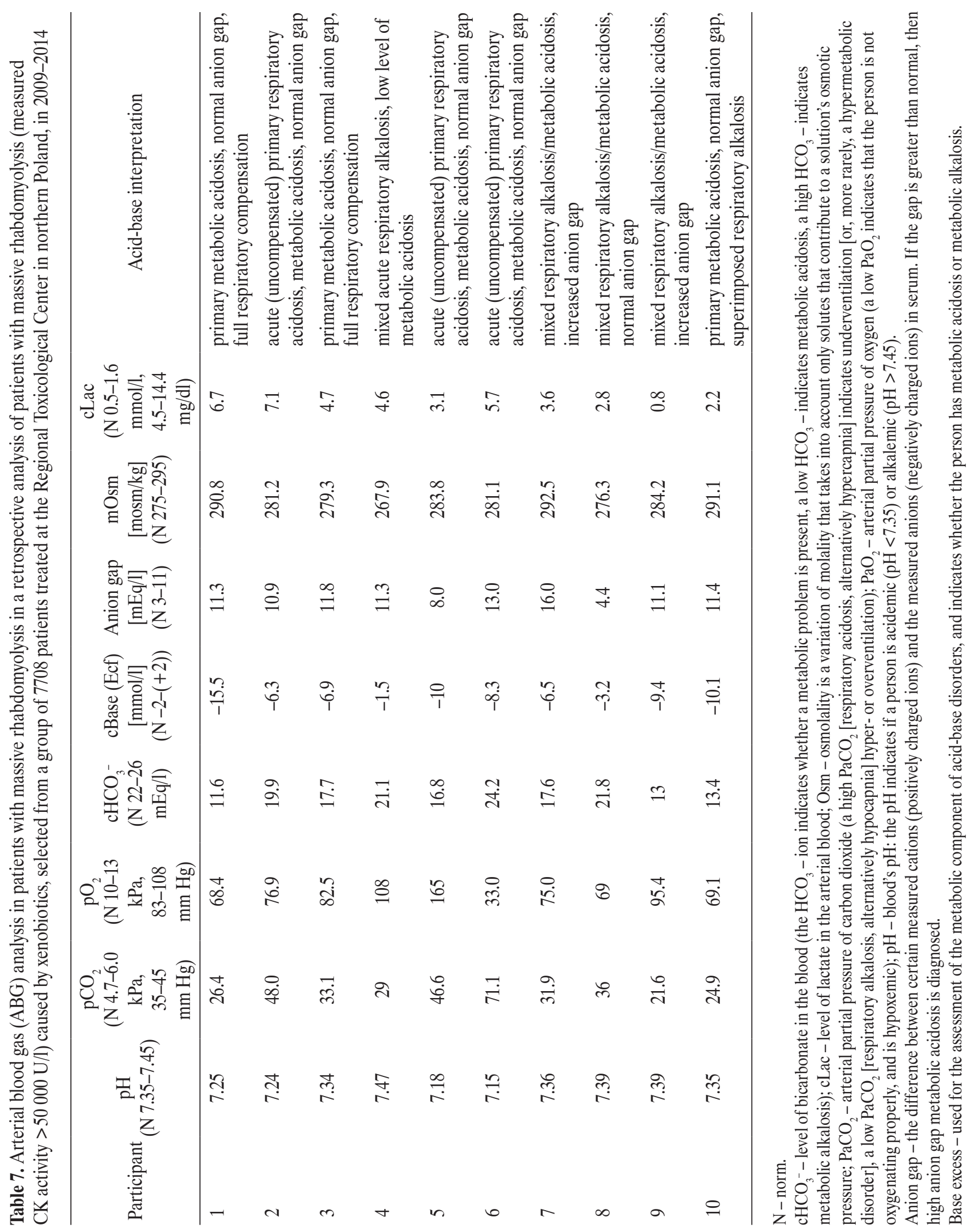


Table 8. Observed complications of severe rhabdomyolysis in a retrospective analysis of patients with massive rhabdomyolysis (measured CK activity $>50000 \mathrm{U} / \mathrm{l}$ ) caused by xenobiotics, selected from a group of 7708 patients treated at the Regional Toxicological Center in northern Poland, in 2009-2014

\begin{tabular}{llcc}
\hline \multicolumn{1}{c}{ Participant } & \multicolumn{1}{c}{ Other major complications } & MOF & Death \\
\hline 1 & pneumonia, hypotension & yes & yes \\
2 & compartment syndrome, hypotension, DIC & yes & no \\
3 & pneumonia & no & no \\
4 & none & yes & no \\
5 & compartment syndrome, DIC & yes & no \\
6 & pneumonia & yes & no \\
7 & none & no & no \\
8 & none & no & no \\
9 & none & no & no \\
10 & pneumonia & yes & \\
\hline
\end{tabular}

DIC - disseminated intravascular coagulation; MOF - multi-organ failure.

ent in 36\%, and CK >166.7 ukat/l (10 $000 \mathrm{U} / \mathrm{l})$ was present in $3 \%$ of the patients.

Every patient in the present study had elevated activity levels of aminotransferases (ALT, AST). However, considering the very strong correlation between CK and ALT/AST, and the lack of a significant correlation between CK and INR (treated here as a marker of hepatic function), the authors concluded that the elevation was, to a large extent, an effect of the release of aminotransferases from damaged muscle tissue rather than a result of liver injury.

Acute renal failure is one of the most dangerous complications of rhabdomyolysis [16], and the need for RRT in those patients is being discussed. The frequency of acute renal failure secondary to rhabdomyolysis is $16-59 \%$, according to published data [14,17-20].

This observation shows, in accordance with Bosch et al. [2], that severe renal failure, leading to anuria and requiring RRT, is seen mainly in patients with very high CK activity levels. The authors have additionally observed that there is a strong positive correlation between a change in creatinine concentration over the first day of hospitalization and the length of hospital stay.
In literature, there is significant variance in the definitions of rhabdomyolysis and kidney injury/failure, as well as in the research methodologies employed. Some studies included patients according to their discharge statistical coding instead of their laboratory test results. Most of those individuals were people with a severe elevation of CK activity, usually <500.1 ukat/l (30 $000 \mathrm{U} / \mathrm{l}$ ), who were admitted to hospital. Little is known about patients with lower CK activity levels. The risk of developing acute kidney injury, the need for RRT and mortality in this group remain unknown [21].

Fluid replacement is a keystone of rhabdomyolysis treatment [22]. Capillary damage and fluid leakage lead to a "functional" dehydration that requires early, aggressive fluid therapy. All of the patients involved received 4-8 1 of fluid i.v. daily, as suggested by other authors [23-25]. Nine patients had acute kidney injury. Only 1 patient had a normal creatinine concentration on admission despite having elevated CK activity. Three patients received treatment with a high volume of fluids $(150-350 \mathrm{ml} / \mathrm{h}$ i.v.) with alkalization (10 $\mathrm{mmol}_{\text {of }} \mathrm{NaHCO}_{3}$ for every $500 \mathrm{ml}$ of crystalloids), which was sufficient to sustain kidney function 
and prevent the need for RRT. However, no studies have actually compared bicarbonate therapy with fluid therapy alone $[23,24]$. Continuous renal replacement therapy (CRRT) provides for fluid removal and solute clearance continuously, $24 \mathrm{~h} /$ day, potentially allowing for less hemodynamic instability in critically ill patients. Intermittent hemodialysis (IHD) is highly effective in achieving solute removal by solute clearance, and fluid removal by ultrafiltration. This method seems to be more convenient for stable patients during recovery and rehabilitation. It involves medical staff for a shorter period.

In many cases, an early recognition of rhabdomyolysis leads to the adequate prevention of the development of renal injury, which protects the renal ability to excrete toxic metabolites and stops the "vicious circle" mechanism. In the cases of severe rhabdomyolysis in which multiple organs are already damaged, patients usually require extracorporeal organ support. The effectiveness of IHD was described by Russel [26].

Takizawa et al. [27] reported on a patient with NMS and severe rhabdomyolysis (CK > 2667.2 ukat/l [160 000 U/l]). The patient was treated with bromocriptine and dantrolene. Additionally, the following aggressive treatment was used: hydration with alkalization, 3 plasmapheresis procedures, 5 days of continuous veno-venous haemodiafiltration and intermittent dialysis performed until day 45 of the disease. In the present study, the authors observed many rhabdomyolysis complications, including metabolic acidosis, hyperkaliemia, hyperphosphatemia, and hypocalcaemia, which can lead to mental state alterations, dysrhythmias, nausea, and vomiting. The release of cellular contents into the bloodstream may lead to hypotonia and renal injury via a mechanism involving fluid translocation from the blood to the damaged muscle tissue [2,9]. Another complication of rhabdomyolysis is the chaotic activation of the coagulation cascade, leading to the development of disseminated intravascular coagulation $[9,28]$. Massive muscular edema may lead to the development of compartment syndrome, with peripheral perfusion deficit and pain [28]. Severe hypotension or sepsis are other factors that increase the risk of renal injury. There are only limited data regarding the mortality of patients with rhabdomyolysis. According to Gabow et al. [20], Cervellin et al. [8], and Bagley et al. [29], the mortality rate of patients with rhabdomyolysis is $8-10 \%$. Jankovic et al. [15] observed mortality in $25.6 \%$ of intoxicated patients with CK activity levels $>4.17$ ukat/l (250 U/l).

The observation made in this study revealed the mortality in patients with CK activity levels $>833.5$ ukat/l ( $50000 \mathrm{U} / \mathrm{l})$ to be $10 \%$. Only $30 \%$ of the patients were discharged after hospitalization lasting $<7$ days. Most patients had to undergo intensive therapy and prolonged stays in the intensive care unit, in some cases followed by rehabilitation in lowerlevel facilities.

This observation shows, in accordance with Keltz et al. [30], that toxic rhabdomyolysis is usually the result of multiple contributing factors.

It should be noted that the size of the studied sample may be too small to draw general conclusions; however, severe rhabdomyolysis is a rare condition, so gathering a large cohort may involve a large, multi-center study. Thus, these observations may prove helpful in the management of patients with severe rhabdomyolysis.

\section{CONCLUSIONS}

The most common cause of massive toxin-induced rhabdomyolysis is the use of psychoactive substances, including ethanol. Most patients developing severe rhabdomyolysis in the study group were diagnosed with substance abuse disorder. The majority of patients presenting with massive toxic rhabdomyolysis had many factors influencing the development of muscle damage. Massive rhabdomyolysis is a pathologic process affecting a number of body systems and constitutes a state of immediate threat to life. Renal replacement therapies are an efficient means of balancing disturbances caused by muscle damage and treating severe rhabdomyolysis complications. Early rec- 
ognition of rhabdomyolysis and aggressive treatment initiation may prevent the need for RRT. A decrease in creatinine concentration over the first day of hospitalization may be indicative of a good prognosis despite a high CK activity level.

\section{REFERENCES}

1. Giannoglou GD, Chatzizisis YS, Misirli G. The syndrome of rhabdomyolysis: pathophysiology and diagnosis. Eur J Intern Med. 2007;18(2):90-100, https://doi.org/10.1016/j.ejim. 2006.09.020.

2. Bosch X, Poch E, Grau JM. Rhabdomyolysis and acute kidney injury. New Engl J Med. 2009;361(1):62-72, https://doi. org/10.1056/NEJMra0801327.

3. Torres PA, Helmstetter JA, Kaye AM, Kaye AD. Rhabdomyolysis: pathogenesis, diagnosis, and treatment. Ochsner J. 2015;15(1):58-69.

4. Bywaters EG. 50 years on: the crush syndrome. BMJ. 1990;301(6766):1412-5, https://doi.org/10.1136/bmj.301.6766. 1412.

5. Melli G, Chaudhry V, Cornblath DR. Rhabdomyolysis: an evaluation of 475 hospitalized patients. Medicine (Baltimore). 2005;84(6):377-85, https://doi.org/10.1097/01.md.0000188565. 48918.41.

6. World Health Organization. International classification of diseases. Geneva: The Organization; 2017.

7. Lazenby RB, Corwin EJ. Handbook of pathophysiology. Philadelphia: Wolters Kluwer/Lippincott Williams \& Wilkins Health; 2011.

8. Cervellin G, Comelli I, Lippi G. Rhabdomyolysis: historical background, clinical, diagnostic and therapeutic features. Clin Chem Lab Med. 2010;48(6):749-56, https://doi.org/10. 1515/CCLM.2010.151.

9. Huerta-Alardín AL, Varon J, Marik PE. Bench-to-bedside review: rhabdomyolysis - an overview for clinicians. Crit Care. 2005;9(2):158-69, https://doi.org/10.1186/cc2978.

10. Childs SG. Rhabdomyolysis. Orthop Nurs. 2005;24(6):4437, https://doi.org/10.1097/00006416-200511000-00011.
11. Zhang MH. Rhabdomyolosis and its pathogenesis. World $\mathbf{J}$ Emerg Med. 2012;3(1):11-5, https://doi.org/10.5847/wjem.j. issn.1920-8642.2012.01.002.

12. Rodriguez-Capote K, Balion CM, Hill SA, Cleve R, Yang L, El Sharif A. Utility of urine myoglobin for the prediction of acute renal failure in patients with suspected rhabdomyolysis: a systematic review. Clin Chem. 2009;55(12):2190-7, https://doi.org/10.1373/clinchem.2009.128546.

13. Sauret JM, Marinides G, Wang GK. Rhabdomyolysis. Am Fam Physician. 2002;65(5):907-12.

14. Veenstra J, Smit WM, Krediet RT, Arisz L. Relationship between elevated creatine phosphokinase and the clinical spectrum of rhabdomyolysis. Nephrol Dial Transpl. 1994; 9(6):637-41, https://doi.org/10.1093/ndt/9.6.637.

15. Janković SR, Jović-Stošić J, Vučinić S, Perković-Vukčević N, Vuković-Ercegović G. Causes of rhabdomyolysis in acute poisonings. Vojnosanit Pregl. 2013;70(11):1039-45, https:// doi.org/10.2298/VSP1311039J.

16. Mehta RL, Kellum JA, Shah SV, Molitoris BA, Ronco C, Warnock DG, et al. Acute kidney injury network: report of an initiative to improve outcomes in acute kidney injury. Crit Care. 2007;11(2):R31, https://doi.org/10.1186/cc5713.

17. Fernandez WG, Hung O, Bruno GR, Galea S, Chiang WK. Factors predictive of acute renal failure and need for hemodialysis among ED patients with rhabdomyolysis. Am J Emerg Med. 2005;23(1):1-7, https://doi.org/10.1016/j.ajem.2004. 09.025 .

18. Delaney KA, Givens ML, Vohra RB. Use of RIFLE criteria to predict the severity and prognosis of acute kidney injury in emergency department patients with rhabdomyolysis. J Emerg Med. 2012;42(5):521-8, https://doi.org/10.1016/j. jemermed.2011.03.008.

19. Ward MM. Factors predictive of acute renal failure in rhabdomyolysis. Arch Intern Med. 1988;148(7):1553-7, https:// doi.org/10.1001/archinte.1988.00380070059015.

20. Gabow PA, Kaehny WD, Kelleher SP. The spectrum of rhabdomyolysis. Medicine (Baltimore). 1982;61(3):141-52, https://doi.org/10.1097/00005792-198205000-00002. 
21. Grunau BE, Pourvali R, Wiens MO, Levin A, Li J, Grafstein E, et al. Characteristics and thirty-day outcomes of emergency department patients with elevated creatine kinase. Acad Emerg Med. 2014;21(6):631-6, https://doi.org/10.1111/ acem.12385.

22. Scharman EJ, Troutman WG. Prevention of kidney injury following rhabdomyolysis: a systematic review. Ann Pharmacother. 2013;47(1):90-105, https://doi.org/10.1345/aph.1R215.

23. Iraj N, Saeed S, Mostafa H, Houshang S, Ali S, Farin RF, et al. Prophylactic fluid therapy in crushed victims of bam earthquake. Am J Emerg Med. 2011;29(7):738-42, https:// doi.org/10.1016/j.ajem.2010.02.018.

24. Talaie H, Emam-Hadi M, Panahandeh R, Hassanian-Moghaddam H, Abdollahi M. On the mechanisms underlying poisoning-induced rhabdomyolysis and acute renal failure. Toxicol Mech Methods. 2008;18(7):585-8, https://doi. org/10.1080/15376510802232167.

25. Altintepe L, Guney I, Tonbul Z, Türk S, Mazi M, Ağca E, et al. Early and intensive fluid replacement prevents acute renal failure in the crush cases associated with spontaneous collapse of an apartment in Konya. Ren Fail. 2007;29(6): 737-41, https://doi.org/10.1080/08860220701460095.

26. Russell TA. Acute renal failure related to rhabdomyolysis: pathophysiology, diagnosis, and collaborative management. Nephrol Nurs J. 2005;32(4):409-17.

27. Takizawa D, Nishikawa K, Hiraoka H, Hinohara H, Saito S, Goto F, et al. Successful management of a patient with neuroleptic malignant syndrome associated with marked elevation of serum creatine kinase. J Anesth. 2004;18(2):135-7, https://doi.org/10.1007/s00540-003-0223-3.

28. Warren JD, Blumbergs PC, Thompson PD. Rhabdomyolysis: a review. Muscle Nerve. 2002;25(3):332-47, https://doi. org/10.1002/mus.10053.

29. Bagley WH, Yang H, Shah KH. Rhabdomyolysis. Intern Emerg Med. 2007;2(3):210-8, https://doi.org/10.1007/s11739007-0060-8.

30. Keltz E, Khan FY, Mann G. Rhabdomyolysis. The role of diagnostic and prognostic factors. Muscles Ligaments Tendons J. 2014;3(4):303-12.

This work is available in Open Access model and licensed under a Creative Commons Attribution-NonCommercial 3.0 Poland License - http://creativecommons.org/ licenses/by-nc/3.0/pl/deed.en. 